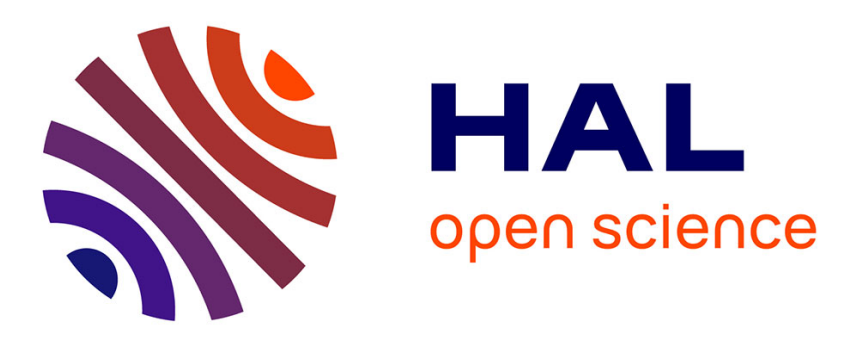

\title{
Synthesis of iron oxide films by reactive magnetron sputtering assisted by plasma emission monitoring
}

\author{
E. Aubry, T. Liu, A. Dekens, Frédéric Perry, S. Mangin, Thomas Hauet, Alain
} Billard

\section{- To cite this version:}

E. Aubry, T. Liu, A. Dekens, Frédéric Perry, S. Mangin, et al.. Synthesis of iron oxide films by reactive magnetron sputtering assisted by plasma emission monitoring. Materials Chemistry and Physics, 2019, 223, pp.360-365. 10.1016/j.matchemphys.2018.11.010 . hal-01950283

\section{HAL Id: hal-01950283 \\ https://hal.science/hal-01950283}

Submitted on 19 Dec 2018

HAL is a multi-disciplinary open access archive for the deposit and dissemination of scientific research documents, whether they are published or not. The documents may come from teaching and research institutions in France or abroad, or from public or private research centers.
L'archive ouverte pluridisciplinaire $\mathbf{H A L}$, est destinée au dépôt et à la diffusion de documents scientifiques de niveau recherche, publiés ou non, émanant des établissements d'enseignement et de recherche français ou étrangers, des laboratoires publics ou privés. 


\title{
Synthesis of iron oxide films by reactive magnetron sputtering assisted by plasma emission monitoring
}

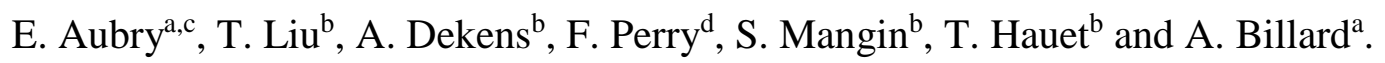

a Institut FEMTO-ST, UMR 6174 CNRS, UTBM, Univ. Bourgogne Franche-Comté, rue Thierry Mieg, Site de Montbéliard, 90010 Belfort cedex, France

b Institut Jean Lamour, UMR 7198 CNRS-Université de Lorraine, 54506 Vandoeuvre-lès-Nancy, France

c Nipson Technology, 12 Avenue des Trois Chênes, Techn'Hom 3, 90000 Belfort, France

d PVDco, 30 rue de Badménil, 54120 Baccarat, France

\begin{abstract}
Iron oxide films were synthesized by pulsed-DC magnetron sputtering from a metallic target in Ar and $\mathrm{O}_{2}$ gas mixtures. Plasma emission monitoring was implemented to accurately control the metalto-oxygen ratio in the coating through the chemical state of the iron target. The intensity of the $\mathrm{Fe}^{*}$ emission line was maintained at a given value (setpoint) in regulating the introduced oxygen flow rate. In addition, the oxidation rate of the growing film was adjusted by controlling the oxidationto-deposition rate ratio as a function of the position of the substrates relative to the magnetron axis. The iron oxide films were characterized by X-ray diffraction, UV-VIS spectrophotometry, electrical measurement and vibrating sample magnetometry. In addition to the crystallization of
\end{abstract}


pure hematite and magnetite phases, both phases coexist in a transition domain for a short range of setpoint depending on the oxidation-to-deposition rate ratio. The electrical, optical and magnetic behaviors of the $\mathrm{FeO}_{\mathrm{x}}$ films suggest that the relative proportion of phases can be tailored in this range. The $\mathrm{FeO}_{\mathrm{x}}$ film behaviors can then be tuned from the hematite semi-conductor properties to the semi-metallic magnetite properties.

\section{Keywords}

$\mathrm{FeO}$; reactive sputtering ; plasma emission monitoring; hematite; magnetite

\section{Introduction}

In the recent years, synthesis of magnetic thin films and nanostructures have been investigated for various applications due to their unique structural, electrical, optical and magnetic properties $[1][2][3][4][5]$. The versatile properties and its abundance make iron oxide an interesting material suitable for a wide range of applications [6][7]. According to the crystallographic phase and to the oxygen content, either a semiconductor hematite $\alpha-\mathrm{Fe}_{2} \mathrm{O}_{3}$ phase or half-metallic magnetite spinel $\mathrm{Fe}_{3} \mathrm{O}_{4}$ phase can be observed resulting in various optical, electrical and magnetic properties [8][9][10]. The hematite and magnetite phases possess a bandgap of approximately 2.2 and $0.1 \mathrm{eV}$, respectively [9]. The hematite exhibits weak ferromagnetism, whereas the magnetite is ferrimagnetic at ambient temperature [11][12]. The magnetite behaves almost as an electrical metallic conductor, while the hematite phase displays electrical insulating property [6]. As examples, hematite can be used as an anode for a lithium-ion battery [13] or for photoelectrochemical water splitting [14], as pigment [15][16][17], in waste water treatment [18], 
as a gas sensor [19][20], or in catalysis [21]. Magnetite can be employed in biomedical [22][23], magnetic printing [24][25], in microelectronics as a microwave-absorbing materials [26][27][28][29], in thermoelectricity [30], or as a thermistor in a bolometer [31].

Since iron oxide films properties strongly depend on their stoichiometry, an accurate control of the oxygen quantity in the growth chamber is required [32]. In conventional reactive sputtering, the reactive gas introduced in the sputtering chamber is generally controlled by its mass flow leading to the formation of an unstable transient sputtering mode between the metallic and the compound sputtering modes. This is the result of chemical reactions on both target and substrate [33]. Some compositions then remain inaccessible in the transient mode [34]. In addition, erosion of the thin magnetic target can generate a drift in the stoichiometry of the film for long deposition time. Several solutions have been proposed to overcome these difficulties, e. g. the alternation of the sputtering mode between the reactive and the metallic sputtering mode either in pulsing the reactive gas [35][36][37] or in pulsing the discharge current [38][39]. Another solution is maintaining the sputtering mode in the unstable transient mode by means of a feedback control system of the reactive gas partial pressure which can be measured indirectly by means of optical emission spectrometer or directly with mass spectrometry [40][41][42][43].

Furthermore, the oxidation of the growing film partially resulting from the direct reaction with the oxygen species of the discharge [44], the oxidation rate is also dependent on the film deposition rate for a given constant oxygen flow rate. With a fixed substrate holder, the deposition rate is strongly influenced by the sample position relative to the magnetron axis, i.e. its incidence angle.

Here, iron oxide films were synthesized by sputtering a Fe metallic target in $\mathrm{Ar}$ and $\mathrm{O}_{2}$ gas mixtures. Optical emission spectroscopy was implemented to monitor the excited $\mathrm{Fe}^{*}$ emission line 
in the vicinity of the target. The spectrometer was connected to a feedback loop system which regulates the oxygen flow rate according to $\mathrm{Fe}^{*}$ emission line intensity. The metal-to-oxygen fluxes ratio at the target surface can then be adjusted in controlling the $\mathrm{Fe}^{*}$ emission line intensity. To check the synthesis quality and the ability to tune the composition with this method, chemical and physical properties were studied as a function of the steady-state setpoint defining the surface coverage of the target and by taking into account the relative position of the substrate relative to the magnetron axis.

\section{Material and methods}

\subsection{Iron oxide films preparation}

The sputtering device consists in a 100 L stainless steel vessel (Alcatel SCM 650). A base pressure of less than $10^{-3} \mathrm{~Pa}$ was obtained with a turbomolecular pump unit. Iron target of $200 \mathrm{~mm}$-diameter and $2 \mathrm{~mm}$-thick was sputtered with a pulsed Advanced Energy Pinnacle Plus+ power supply and a current density set at $64 \mathrm{~A} \mathrm{~m}^{-2}$. Fused silica glass slides were used as substrates. The substrate holder is located at $13 \mathrm{~cm}$ from the Fe target. For each run, 4 substrates were placed at different distances from the magnetron target axis resulting in different incidence angles relatively to the normal of the substrate holder $(\alpha)$. In other words, the farther away the sample is to the magnetron axis, the higher the incidence angle. Ar and $\mathrm{O}_{2}$ gases flow rates were controlled with MKS flowmeters, and MKS Baratron gauge was used to measure the total pressure. Only Ar gas was regulated at constant flow rate $(30 \mathrm{sccm})$, oxygen being monitored in real time thanks to the closed loop control system. 
The feedback loop system consists of an optical fiber which collects the light emitted from the discharge near the target and sends it to a photomultiplier tube (Hamamatsu R 636) that equips a Roper Scientific SpectraPro 500i spectrometer. Computer software monitors the intensity of the excited $\mathrm{Fe}^{*}$ emission line at $(385.99 \mathrm{~nm})$ and regulates the $\mathrm{O}_{2}$ gas flowmeter as a function of the setpoint. The sputtering of the Fe target in a pure Ar atmosphere defines the $100 \%$ of the setpoint. Consequently, a decrease in the setpoint means that the target coverage increases and hence, the sputtering rate decreases.

\section{2 $\mathrm{FeO}_{\mathrm{x}}$ films characterization}

The thickness was determined from the cross-sections of the films via a Field Emission Scanning Electron Microscope (FE-SEM JEOL JSM -7800F). The thickness of the coatings ranges from to 1.2 to $2.5 \mu \mathrm{m}$. The structural features of the coatings were investigated by using a Bruker D8 focus diffractometer (Co $\mathrm{K}_{\alpha}$ radiation) equipped with the LynxEye linear detector in a Bragg Brentano configuration. The total transmittance and reflectance of the coatings were measured with a Shimadzu UV-3600 spectrophotometer equipped with ISR-3100 integrating sphere in the range 200-1500 nm. Standard white board $\mathrm{BaSO}_{4}$ was used for the baseline. The resistivity of the coating was determined from the sheet resistance measured using conventional four probe method (Jandel system). Magnetometry measurements were performed with a vibrating sample magnetometer (Lakeshore model 7300) at room temperature with a magnetic field (up to 1T) applied in the plane of the films. 


\section{Results and discussion}

\subsection{Deposition rate of $\mathrm{FeO}_{\mathrm{x}}$ films}

Fig. 1 exhibits the evolution of the deposition rate as a function of the setpoint for different incidence angles. From 50 to $80 \%$ of setpoint, the deposition rate increases with the setpoint. The rarefaction of the oxygen partial pressure in the discharge with the setpoint increase lowers the target poisoning and therefore induces a higher deposition rate. In addition, it can be verified that the deposition rate also depends on the incidence angle, namely the deposition rate decreases with the increase of the incidence angle mainly due to the higher target-to-substrate distance thus to the dispersion of the sputtered flux and also to the increase of the receiving surface for a given solid

angle. These results point out that the deposition rate depends on the position of the sample relative to the magnetron axis. The oxidation of the coatings resulting partially from a direct oxidation [35], and if the quantity of oxygen received by the samples with the sputtered species flux whatever the incidence angle is assumed constant, then a variation of the oxygen introduced in the coating with the deposition rate and thus the incidence angle is then expected.

At $90 \%$, the deposition rate becomes constant with the incidence angle. When the pure metallic sputtering mode is reached (100\%), the deposition rate at low incidence angle (closed to the normal of the surface) becomes lower than that observed at higher incidence angles. The absence of oxygen at the target surface would alter the binding energy of the surface Fe atoms and the energy of the ions striking the target surface. Consequently, the emission law between a metallic sputtering mode and transition sputtering mode would be modified. A less directional emission flux (under cosine angular distribution) would be expected in the metallic mode in agreement with the voltage drop of the target [45] and could explain the inversion of the deposition rate with the incidence angle. Furthermore, an anomaly of the deposition rate can be observed in a short range of setpoint between 
about 67.5 to $75 \%$. It was already reported that the deposition rate analysis can give evidence of structural changes [46], thus some structural and/or microstructural events could then be expected.

\subsection{Structure of the $\mathrm{FeO}_{\mathrm{x}}$ films}

XRD patterns of the iron oxide films sputtered with different setpoints are shown in Fig. 2. At incidence angle close to the normal of film surface $\left(4^{\circ}\right)$, the films exhibit hexagonal structure of $\alpha$ $\mathrm{Fe}_{2} \mathrm{O}_{3}$ (space group $\mathrm{R} \overline{3} \mathrm{c}$ ) from $50 \%$ up to a setpoint of $67.5 \%$. A low setpoint and an incidence angle close to the direction normal to the surface favors a [104] preferential orientation of the hematite phase. For a narrow range (from 70 to $75 \%$ ), a relatively poor crystallization of both hematite and magnetite (space group $\mathrm{Fd} \overline{3} \mathrm{~m}$ ) structures is observed. The proximity of the peaks of the hematite and magnetite and their relative low intensity makes their differentiation and their quantitative analysis complex. Between 77.5 and $80 \%$, only magnetite phase is detected. A [400] preferential orientation of the magnetite phase is observed at low incidence angle and setpoint (77.5 $\%$ ), while the phase crystallizes along to the [311] direction by increasing the setpoint and the incidence angle. At $90 \%$, a mixture of magnetite and $\alpha$-Fe phases crystallizes. The structural evolution with the setpoint is coherent with the introduced oxygen quantity in the chamber and with the phase diagram of iron-oxygen. The metastable FeO wüstite phase crystallizing only at temperature higher than $570^{\circ} \mathrm{C}$ is not detected. The setpoint range corresponding to the poor crystallization of a mixture of hematite and magnetite phases can be correlated to the domain where a deposition rate anomaly was observed. Incidence angle only affects the setpoint range where both hematite and magnetite phases coexist. In fact, this domain shrinks and shifts to higher setpoint when the incidence angle increases to completely disappear at $\alpha$ higher than $21^{\circ}$. In addition, it 
should be noticed that the diminution of the X-ray intensity corresponding to the $\alpha$-Fe (110) reflection with the incidence angle increase is mainly ascribed to a change in the preferential orientation $\left((110)\right.$ at $\alpha=4^{\circ}$ to $(211)$ at $\left.\alpha=27^{\circ}\right)$ rather than a film thickness decrease.

\subsection{Optical properties of the $\mathrm{FeO}_{\mathrm{x}}$ films}

Fig. 3 presents the average transmittance calculated in the wavelengths range included between 700 to $1300 \mathrm{~nm}$ corresponding to the transparent domain for photons of energy lower than the threshold of the fundamental absorption involving the excitation of electron from the valence band to the conduction band. It can be clearly seen that hematite films deposited with a setpoint of $50 \%$ exhibit a relatively high transparency, higher than $50 \%$. An increase of the setpoint leads to the progressive decrease of the transparency of the film that becomes fully opaque over $77.5 \%$. Furthermore, the incidence angle increase induces a shift of this transition domain towards higher setpoint and to the decrease of the slope in absolute value. Indeed, at higher incidence angle or lower deposition rate, the oxidation rate of the film increases. Consequently, the hematite structure and thus the transparency is maintained at higher incidence angle for a constant setpoint. It is necessary to decrease the quantity of oxygen in the chamber to a higher setpoint to crystallize magnetite structure and to win in opacity for coatings deposited at high incidence angle.

The progressive drop of the transmittance is observed in a domain of composition where a mixture of hematite and magnetite coexist, and is assumed to be correlated to the phase proportion.

Film growth with an oblique incidence is a well-known phenomenon. The microstructure and the morphology can strongly be modified according to the incidence angle value, leading to the

presence of porosity [47]. As previously observed by Charles et al., the diminution of the 
transmittance with the incidence angle could be also ascribed to a change in the porosity of the microstructure [48]. However, the value of incidence angle used in this study seems to be too low to have a significant effect on the optical properties.

It can be noticed that the edge of the coexistence domain does not correspond exactly with the previous X-ray observations, probably because the proportion of the secondary phase is too weak to be detected by X-ray analysis.

In the transmittance drop domain, a change in the slope between 67.5 to $75 \%$ can be observed. This event is consistent with the irregularity of the deposition rate previously observed.

Hematite-type films which show a relatively high transparency exhibit an absorption edge in the range 570-600 $\mathrm{nm}$ at the origin of the reddish colour of the coatings. The optical band gap of hematite-type film has been experimentally determined using Tauc's formula (see Fig. 4) [49]:

$(\alpha h v)=A\left(h v-E_{g}\right)^{n}$

Where $\alpha$ is the absorption coefficient obtained from transmittance and reflectance spectra, $\mathrm{A}$ is a constant, and $\mathrm{n}$ is equal to $1 / 2$ for allowed direct transition or 2 allowed indirect transitions. The absorption coefficient $\alpha$ has been determined from the transmittance T( $\lambda)$ and reflectance $R(\lambda)$ spectra in using the following equation :

$\alpha(\lambda)=(1 / t) \ln \{(1-R(\lambda)) / T(\lambda)\}$

where $\mathrm{t}$ is the thickness of the film. The direct and indirect band gaps of hematite films deposited with a setpoint lower than $67.5 \%$ are about 2.06-2.17 and 1.78-1.96 eV respectively, in agreement with previous studies [50][51]. The incidence angle has no influence on the electronic transitions in pure hematite films. However, the crystallization of magnetite which is sensitive to the incidence 
angle and to the setpoint strongly affects the optical band gap of the films inducing a red shift of the absorption edge in addition to increase the opacity of the films.

\subsection{Electric properties of the $\mathrm{FeO}_{\mathrm{x}}$ film}

The electrical resistivity at room temperature of the $\mathrm{FeO}_{\mathrm{x}}$ films has been measured using a four probe method (see Fig. 5). The resistivity of the hematite films is stabilized at $10^{5} \Omega \mathrm{cm}$, which is almost the measurement limit of the apparatus, and does not allow more accurate measurement whereas a large variation in the hematite film conductivity $\left(10^{4}\right.$ to $\left.10^{10} \Omega \mathrm{cm}\right)$ was reported by Miller et al. [50]. The electrical resistivity of the pure magnetite (77.5 to $80 \%)$ and iron phases $(100 \%)$ are $10^{-2}-10^{-1}$ and $310^{-4} \Omega \mathrm{cm}$ respectively, which is in agreement with the values reported by Mauvernay et al. $\left(10^{-2} \Omega \mathrm{cm}\right)$ [52] or by Ohta et al. $\left(1-10^{-1} \Omega \mathrm{cm}\right)$ [53]. The increase of the setpoint induces a drop of the electrical resistivity. Moreover it can be observed that the incidence angle affects the resistivity drop. Since the electrical resistivity depends on the phase proportion, the decrease of the electrical resistivity can be ascribed to the increase of the fraction of the conductive semi-metallic magnetite phase, in agreement with the optical properties. With the increase of the incidence angle the hematite crystallization prevails over that of the magnetite phase leading to higher electrical resistivity. It is noteworthy that the low incidence angles combined with a low working pressure $\left(\mathrm{P}_{\mathrm{T}}=0.3 \mathrm{~Pa}\right)$ used in this study are insufficient to explain such electrical resistivity behavior only by the change of the porosity with the incidence angle [54].

In addition an irregularity in the resistivity drop with the setpoint is observed in a limited domain (from 67.5 to $72.5 \%$ ) corresponding to the previous observations. Indeed, an increase in the resistivity is observed in this domain for low incidence angle. The amplitude of this increase 
diminishes for higher incidence angle (the slope changes without inversion), i.e. for films in which the hematite fraction prevails over that of magnetite.

\subsection{Magnetic properties of the $\mathrm{FeO}_{\mathrm{x}}$ films}

From M-H loops of the $\mathrm{FeO}_{\mathrm{x}}$ thick films deposited on fused silica glass substrates, the coercivity and saturation magnetization have been determined (see Fig. 6). Hematite films $(<67.5 \%)$ exhibit very small magnetization at saturation, in agreement with previous studies $\left(1-2 \mathrm{emu} \mathrm{cm}^{-3}\right)$ [55]. The crystallization of the magnetite with the setpoint increase leads to the increase of the coercivity to reach a maximum, and to a slight increase of the saturation magnetization which is in agreement with an increase of magnetite phase fraction not only with the setpoint but also with the incidence angle. Similar results have been obtained with iron-chromiun oxide particles for which the saturation magnetization increases with the presence of magnetite phase in hematite [56]. The position of the coercivity maximum shifts to higher setpoint with the increase of the incidence angle. The coercivity of the magnetite films (77.5 and $80 \%$ ) is included between 312 to 426 Oe and their saturation magnetizations are about 243-424 $\mathrm{emu} \mathrm{cm}^{-3}$ which is lower than the bulk values (477 $\mathrm{emu}^{-3}$ ) [10]. The magnetization of the films having a mixture of magnetite and metallic iron remains quite constant though the crystallization of iron. Their coercivity decreases to 100$150 \mathrm{Oe}$, and then to less than 100 Oe for pure iron film. The saturation magnetization of iron film is lower than the bulk value $\left(1700 \mathrm{emu}^{-3}\right)$. Many factors such as the quality of the crystallization [57], the chemical ordering at the nanoscale [58] or the presence of internal porosity [59] could explain the lower saturation magnetization values of the coatings than that of the expected bulk value. 


\section{Conclusions}

Thick iron oxide films were synthesized by pulsed-DC reactive magnetron sputtering assisted by plasma emission monitoring to accurately control the oxygen-to-metal ratio at the magnetic target surface to take into account its ageing. The intensity of the $\mathrm{Fe}^{*}$ emission line was maintained at given value (setpoint) in regulating the introduced oxygen flow rate thanks to a closed loop control. In addition, it was demonstrated that the stoichiometry of the growing film can also be adjusted by controlling the oxidation-to-deposition rate of the growing film as a function of the substrate positions relative to the magnetron axis. $\mathrm{FeO}_{\mathrm{x}}$ films crystallize in pure hematite or in pure magnetite phase. A poor crystallization of a mixture of hematite and magnetite phases has been observed for intermediate setpoints resulting in specific electrical, optical and magnetic properties. Although the XRD analysis of phases mixture does not allow precise quantification of their relative proportion, optical, electrical and magnetic behaviors suggest that the relative proportion of phases can be tuned for a short range of setpoint. The increase of the oxidation-to-deposition ratio with the incidence angle shifts the coexistence domain to higher setpoint values. The electrical resistivity can be tailored from insulating to conductive according to the nature of the predominant phase hematite or magnetite reciprocally. The level of magnetization, the coercivity and some optical properties such as the transparency or the optical band gap can also be controlled as a function of the relative phase fraction. Finally an anomaly in the optical, electrical or magnetic behaviors is observed for about 70 to $75 \%$ of setpoint. Although the amplitude of this event seems linked to the presence of magnetite, this phenomenon remains unclear and requires deeper investigations. 


\section{Acknowledgement}

The authors thank the French National Agency for its grant of the research project (ANR-11RMNP-004), the "Pays de Montbéliard Agglomération", and Christopher Slone for his help of English corrections. 


\section{References}

[1] Grant V.M. Williams, Tushara Prakash, John Kennedy, Shen V. Chong, Sergey Rubanov, Spindependent tunneling in magnetite nanoparticles, J. Mag. Mag. Mater. 460 (2018) 229

[2] J. Kennedy, J. Leveneur, G. V. M. Williams, D. R. G. Mitchell, A. Markwitz, Fabrication of surface magnetic nanoclusters using low energy ion implantation and electron beam annealing, Nanotechnology 22 (2011) 115602

[3] T. Prakash, G. V. M. Williams, J. Kennedy, S. Rubanov, High spin-dependent tunneling magnetoresistance in magnetite powders made by arc-discharge, J. Appl. Phys. 120 (2016) 123905

[4] Tushara Prakash, Grant V.M. Williams, John Kennedy, Sergey Rubanov, Formation of magnetic nanoparticles by low energy dual implantation of $\mathrm{Ni}$ and $\mathrm{Fe}$ into $\mathrm{SiO}_{2}$, J. Alloy Compd. 667 (2016) 255

[5] K. Kaviyarasu, P.P. Murmu, J. Kennedy, F.T. Thema, Douglas Letsholathebe, L. Kotsedi, M. Maaza, Structural, optical and magnetic investigation of $\mathrm{Gd}$ implanted $\mathrm{CeO}_{2}$ nanocrystals, Nucl. Instrum. Meth. B 409 (2017) 147

[6] Gareth S. Parkinson, Iron oxide surfaces, Surf. Sci. Rep. 71 (2016) 272

[7] Damien Faivre, Richard B. Frankel (Foreword by), Iron oxides: from nature to applications, Wiley-VCH, Weinheim, 2016 
[8] M. Mohapatra, S. Anand, Synthesis and applications of nano-structured iron oxides/hydroxides - a review, Int. J. Eng. Sci. Technology 2 (2010) 127

[9] R. M. Cornell, U. Schwertmann, The Iron Oxides: Structure, Properties, Reactions, Occurences and Uses, Wiley-VCH, Weinheim, 2003

[10] Arturo I. Martinez, M.A. Garcia-Lobato, Dale L. Perry, Study of the properties of iron oxide nanostructures, in New Nanotechnology Developments, Nova Science Publishers, 2009, NewYork

[11] D. Ramimoghadam,S. Bagheri, S. Bee Abd Hamid, Progress in electrochemical synthesis of magnetic iron nanoparticles, J. Mag. Mag. Mater. 368 (2014) 207

[12] B. D. Cullity, C. D. Graham, Introduction to magnetic materials, $2^{\text {nd }}$ edition, Willey \& Sons, 2009, New Jersey

[13] Xiadong Zheng, Jianlong Li, A review of research on hematite as anode material for lithium-ion batteries, Ionics 20 (2014) 1651

[14] Andebet Gedamu Tamirat, John Rick, Amare Aregahegn Dubale, Wei-Nien Su, Bing-Joe Hwang, Using hematite for photoelectrochemical water splitting: a review of current progress and challenges, Nanoscale Horiz. 1 (2016) 243

[15] Olga Opuchovic, Aivaras Kareiva, Historical hematite pigment: synthesis by an aqueous sol-gel method, characterization and application for the colouration of ceramic glazes, Ceram. Int. 41 (2015) 4504

[16] S.R. Prim, M.V. Folgueras, M.A. de Lima, D. Hotza, Synthesis and characterization of hematite pigment obtained from a steel waste industry, J. Hazard. Mater. 192 (2011) 1307 
[17] Kaustubh Shrimali, Jiaqi Jin, Behzad Vaziri Hassas, Xuming Wang, Jan D. Miller, The surface state of hematite and its wetting characteristics, J. Colloid. Interf. Sci. 477 (2016) 16

[18] B. Saiphaneendra, Tejas Saxena, Satyapaul A. Singh, Giridhar Madras, Chandan Srivastava, Synergistic effect of co-existence of hematite ( $\alpha$-Fe2O3) and magnetite (Fe3O4) nanoparticles on graphene sheet for dye adsorption, J. Environ. Chem. Eng. 5 (2017) 26

[19] Hongying Hao, Dandan Sun, Yanyan Xu, , Ping Liu, Guoying Zhang, Yaqiu Sun, Dongzhao Gao, Hematite nanoplates: controllable synthesis, gas sensing, photocatalytic and magnetic properties, J. Colloid. Interf. Sci. 462 (2016) 315

[20] Nguyen Duc Cuong, Tran Thai Hoa, Dinh Quang Khieu, Nguyen Duc Hoa, Nguyen Van Hieu, Gas sensor based on nanoporous hematite nanoparticles: effect of synthesis pathways on morphology and gas sensing properties, Curr. Appl. Phys. 12 (2012) 1355

[21] Zeheng Yang, Kun Wang, Zongming Shao, Yuan Tian, Gongde Chen, Kai Wang, Zhangxian Chen, Yan Dou, Weixin Zhang, In-situ preparation of $\mathrm{Fe}_{2} \mathrm{O}_{3}$ hierarchical arrays on stainless steel substrate for high efficient catalysis, J. Solid. State Chem. 246 (2017) 278

[22] Ajay Kumar Gupta, Mona Gupta, Synthesis and surface engineering of iron oxide nanoparticles for biomedical applications, Biomaterials 26 (2005) 3995

[23] Wei Wu, Zhaohui Wu, Taekyung Yu, Changzhong Jiang, Woo-Sik Kim, Recent progress on magnetic iron oxide nanoparticles: synthesis, surface functional strategies and biomedical applications, Sci. Technol. Adv. Mat. 16 (2015) 023501

[24] E. Schlömann, Theory of magnetographic printing, IEEE Trans. Magn.10 (1974) 60 
[25] D. Jeanniot, J.C. Bouchand, G. Sache, RF sputtered CoCr for magnetography, J. Appl. Phys. 63 (1988) 3962

[26] Fanbin Meng, Rui Zhao, Yingqing Zhan, Yajie Lei, Jiachun Zhong, Xiaobo Liu, One-step synthesis of Fe-phthalocyanine/Fe3O4 hybrid microspheres, Mater. Lett. 65 (2011) 5000

[27] Yu-Jen Chou, Lih-Shan Chen, Mau-Phon Houng, High-frequency noise absorption of Ag$\mathrm{Fe}_{3} \mathrm{O}_{4}$ films on microstrip transmission line, IEEE Trans. Magn. 51 (2015) 9600104

[28] Jue Liu, Min Zeng, Ronghai Yu, Xiaofang Liu, Minggang Zhu, Size influence to the highfrequency properties of granular magnetite nanoparticles, IEEE Trans. Magn. 50 (2014) 2801304

[29] Rasim A. Alizade, Study of nanocomposite permittivity on the base of magnetite nanoparticles $\left(\mathrm{Fe}_{3} \mathrm{O}_{4}\right)$ and polymeric matrix: polyethylene, polystyrene in electromagnetic field, IEEE Trans. Magn. (2016), early access

[30] Jin-A Kim, Sang-Kwon Lee, Soon-Gil Yoon, Thermoelectric property of $\mathrm{Fe}_{3} \mathrm{O}_{4}$ thin films grown onto the $\mathrm{SiO}_{2}(250 \mathrm{~nm}) / \mathrm{Si}$ and $\mathrm{c}-\mathrm{Al}_{2} \mathrm{O}_{3}(0001)$ substrate at $573 \mathrm{~K}$ using pulsed laser deposition, Sensor Actuat. B-Chem. 204 (2014) 622

[31] L. Puech, Élaboration et caractérisations de couches minces de magnétite pour des applications microbolométriques, Thèse de l'Université Toulouse III - Paul Sabatier, 2009, in french

[32] Z.-J. Zhou, J.-J. Yan, Sputtering iron oxide films by a water vapor process, J. Mag. Mag. Mater. 115 (1992) 87 
[33] A. G. Spencer, R. P. Howson, R. W. Lewin, Pressure stability in reactive magnetron sputtering, Thin Solid Films 158 (1988) 141

[34] J. Musil, P. Baroch, J. Vlček, K. H. Nam, J. G. Han, Reactive magnetron sputtering of thin films: present status and trends, Thin Solid Films 475 (2005) 208

E. Aubry, S. Weber, A. Billard, N. Martin, Silicon oxynitride thin films synthesised by the reactive gas pulsing process using rectangular pulses, Appl. Surf. Sci. 257 (2011) 10065

[36] W. D. Sproul, D. J. Christie, D. C. Carter, S. Berg, T. Nyberg, Proceedings of the $46^{\text {th }}$ Annual SVC Technical Cenference, Society of Vacuum Coaters, San Francisco, CA, 2003, pp. 98

[37] E. Aubry, S. Weber, A. Billard, N. Martin, Enhanced tunability of the composition in silicon oxynitride thin films by the reactive gas pulsing process, Appl. Surf. Sci. 290 (2014) 148

[38] A. Billard, F. Perry, C. Frantz, Stable and unstable conditions of the sputtering mode by modulating at low frequency the current of a magnetron discharge, Surf. Coat. Technol. 94-95 (1997) 345

[39] F. Perry, A. Billard, An investigation of the pulse characteristics on the deposition rate of reactively sputtered titanium films synthesized with a low-frequency modulation of the discharge current, C. Frantz, Surf. Coat. Technol. 94-95 (1997) 339

[40] S. Schiller, U. Heisig, K. Steinfelder, J. Strümpfel, Proc. Int. Conf. on Ion Plating and Allied Techniques, London, 1979, p. 211

[41] A. F. Hmiel, Partial pressure control of reactively sputtered titanium nitride, J. Vac. Sci. Technol. A 3 (1985) 592 
[42] W. D. Sproul, High rate reactive sputtering process control, Surf. Coat. Technol. 33 (1987) 73

[43] A. Brudnik, H. Czternastek, K. Zakrzewska, M. Jachimowski, Plasma-emission-controlled d.c. magnetron sputtering of $\mathrm{TiO}_{2-x}$ thin films, Thin Solid Films 199 (1991) 45

[44] P. Carlsson, C. Nender, H. Barankova, S. Berg, Reactive sputtering using two reactive gases, experiments and computer modeling, J. Vac. Sci. Technol. A 11 (1993) 1534

[45] G. K. Wehner, D. Rosenberg, Angular distribution of sputtered material, J. Appl. Phys. 31 (1960) 177

[46] D. Horwat, M. Dehmas, E. Aubry, J. Zollinger, S. Migot, J.F. Pierson, Properties of nanocrystalline and nanocomposite $\mathrm{W}_{\mathrm{x}} \mathrm{Zr}_{1-\mathrm{x}}$ thin films deposited by co-sputtering, Intermetallics 17 (2009) 421

[47] A. Besnard, N. Martin, F. Stahl, J.-Y. Rauch, Metal-to-dielectric transition induced by annealing of orientated titanium thin films, Functional Materials Letters 6 (2013) 50051

[48] C. Charles N. Martin, M. Devel, J. Ottitrault, A. Billard, Correlation between structural and optical properties of $\mathrm{WO}_{3}$ thin films sputter deposited by glancing angle deposition, Thin Solid Films 534 (2013) 275

[49] J. Kennedy, P.P. Murmu, J. Leveneur, A. Markwitz, J. Futter, Controlling preferred orientation and electrical conductivity of zinc oxide thin films by post growth annealing treatment, Appl. Surf. Sci. 367 (2016) 52

[50] E. L. Miller, D. Paluselli, B. Marsen, R. E. Rocheleau, Low-temperature reactively sputtered iron oxide for thin films device, Thin Solid Films 466 (2004) 307 
[51] M.F. Al-Kuhaili, M. Saleem, S.M.A. Durrani, Optical properties of iron oxide $\left(\alpha-\mathrm{Fe}_{2} \mathrm{O}_{3}\right)$ thin films deposited by the reactive evaporation of iron, J. Alloy Compd. 521 (2012) 178

[52] B. Mauvernay, L. Presmanes, S. Capdeville, V.G. de Resende, E. De Grave, C. Bonningue, $\mathrm{Ph}$. Tailhades, Elaboration and characterization of $\mathrm{Fe}_{1-\mathrm{x}} \mathrm{O}$ thin films sputter deposited from magnetite target, Thin Solid Films 515 (2007) 6532

[53] S. Ohta, A. Terada, Direct preparation of $\gamma-\mathrm{Fe}_{2} \mathrm{O}_{3}$ thin film recording media by R.F. sputtering technique, Thin Solid Films 143 (1986) 73

[54] A. Besnard, N. Martin, L. Carpentier, B. Gallas, A theoretical model for the electrical properties of chromium thin films sputter deposited at oblique incidence, J. Phys. D Appl. Phys. 44 (2011) 215301

[55] Pawan Kumar, Raj Kumar Singh, Nitin Rawat, Partha Bir Barman, Subhash Chander Katyal, Hwanchol Jang, Heung-No Lee, Rajesh Kumar, A novel method for controlled synthesis of nanosized hematite $\left(\alpha-\mathrm{Fe}_{2} \mathrm{O}_{3}\right)$ thin film on liquid-vapor interface, J. Nanopart. Res. $15(2013) 1532$

[56] Dang Phu Nguyen, Quoc Tuan Tran, Xuan Sy Trinh, Thanh Cao Hoang, Hoang Nam Nguyen and Hoang Hai Nguyen, Crystallization and magnetic properties of amorphous ironchromium oxide nanoparticles synthesized by sonochemistry, Adv. Nat. Sci.: Nanosci. Nanotechnol 3 (2012) 015017

[57] J. Dash, Shiva Prasad, N. Venkataramani, R. Krishnan, Pran Kishan, Nitendar Kumar, S. D. Kulkarni, S. K. Date, Study of magnetization and crystallization in sputter deposited LiZn ferrite thin films, J. Appl. Phys. 86 (1999) 3303 
[58] V.I. Tkatch, S.G. Rassolov, V.V. Popov, V.Yu. Kameneva, O.A. Petrenko, Thermal stability and saturation magnetization of a new series of amorphous $\mathrm{Fe}_{80-\mathrm{x}} \mathrm{Co}_{\mathrm{x}} \mathrm{P}_{14} \mathrm{~B}_{6}(20 \leq \mathrm{x} \leq 40)$ alloys, Mater. Lett. 58 (2004) 2988

[59] H. Onishi, S. K. Hyun, H. Nakajima, S. Mitani, K. Takanashi, K. Yakushiji, Magnetization process of lotus-type porous metals, J. Appl. Phys. 103 (2008) 093539 
Figures caption

Fig. 1 Dependence of the deposition rate with the setpoint for different incidence angles

Fig. 2 X-ray diffractograms of the sputtered iron oxide films as a function of the setpoint and for different incidence angle black arrows: theoretical diffraction lines of $\mathrm{Fe}_{2} \mathrm{O}_{3}(\mathrm{H}), \mathrm{Fe}_{3} \mathrm{O}_{4}(\mathrm{M})$ and $\mathrm{Fe}$ (F)

Fig. 3 Average transmittance calculated from 700 to $1300 \mathrm{~nm}$ of iron oxide films deposited with different incidence angle as a function of the setpoint

Fig. 4 Dependence of the direct (a) or indirect (b) transitions in hematite-type films on the setpoint and on the incidence angle

Fig. 5 Dependence of the electrical resistivity of the iron oxide films on the setpoint

Fig. 6 Evolution of the magnetic properties of the iron oxide films with the setpoint (coercivity field, magnetization at saturation) 
Fig. 1

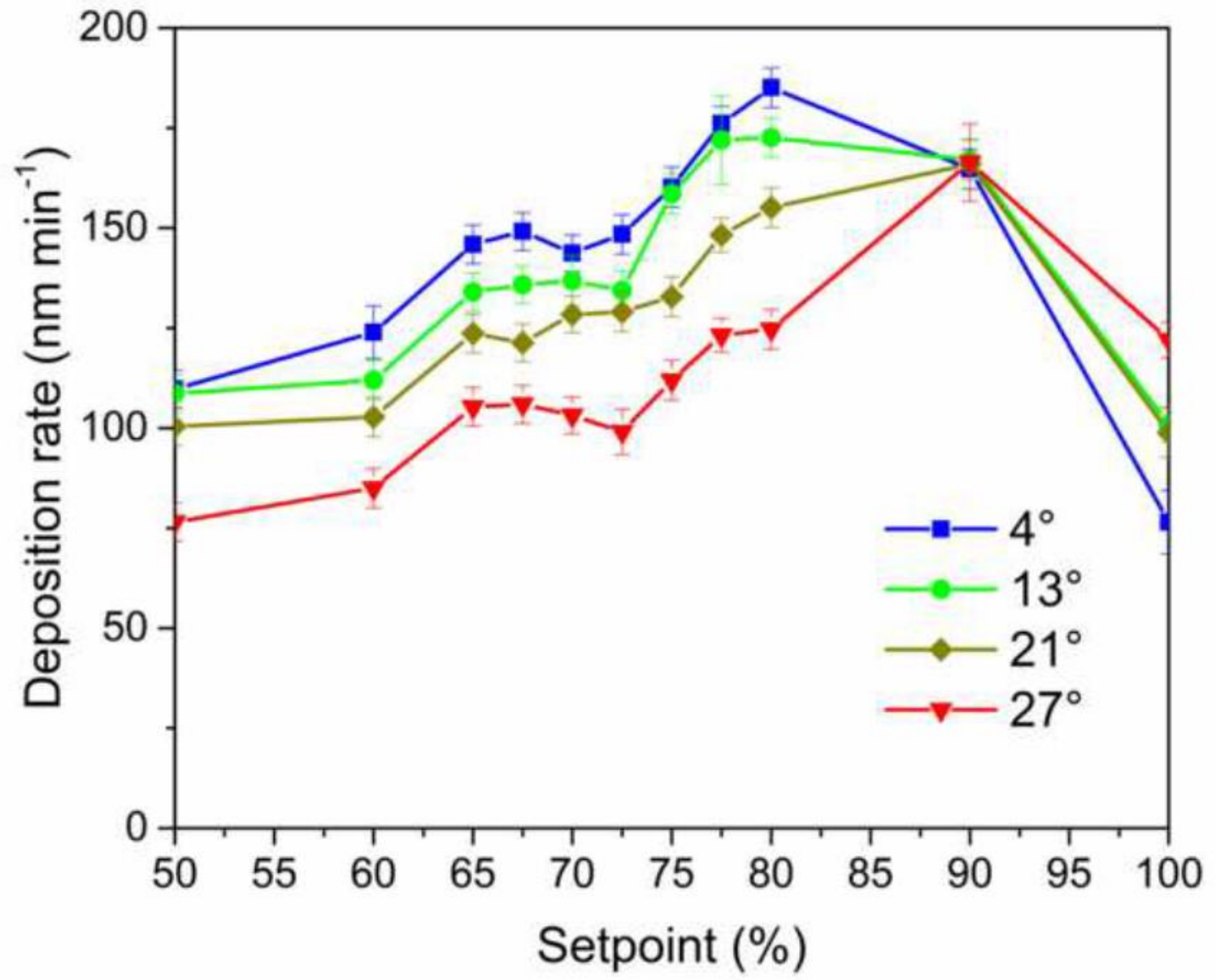


Fig. 2
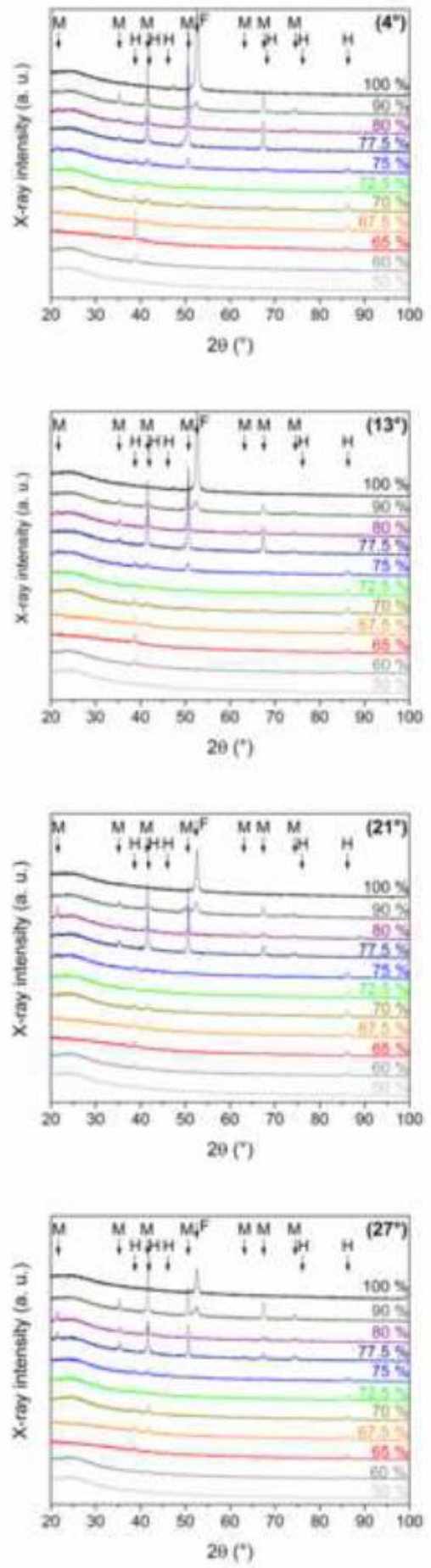
Fig 3

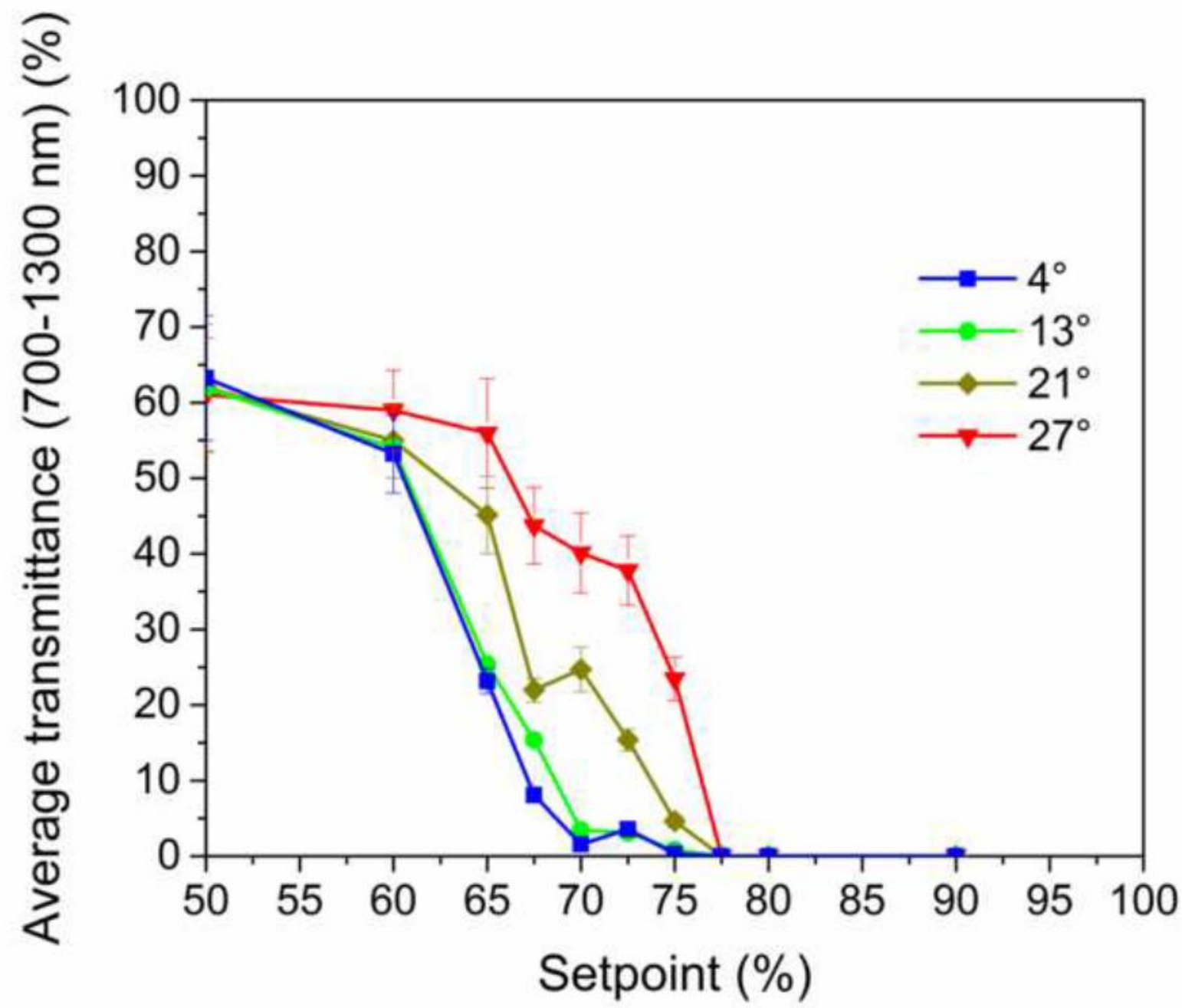


Fig 4
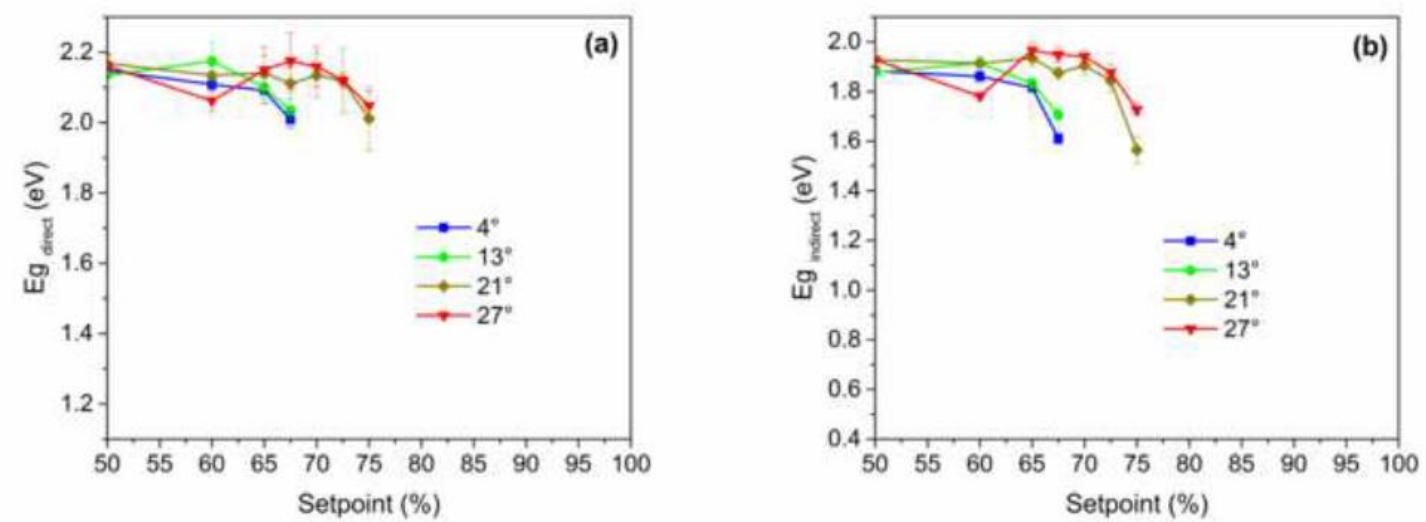

Fig 5

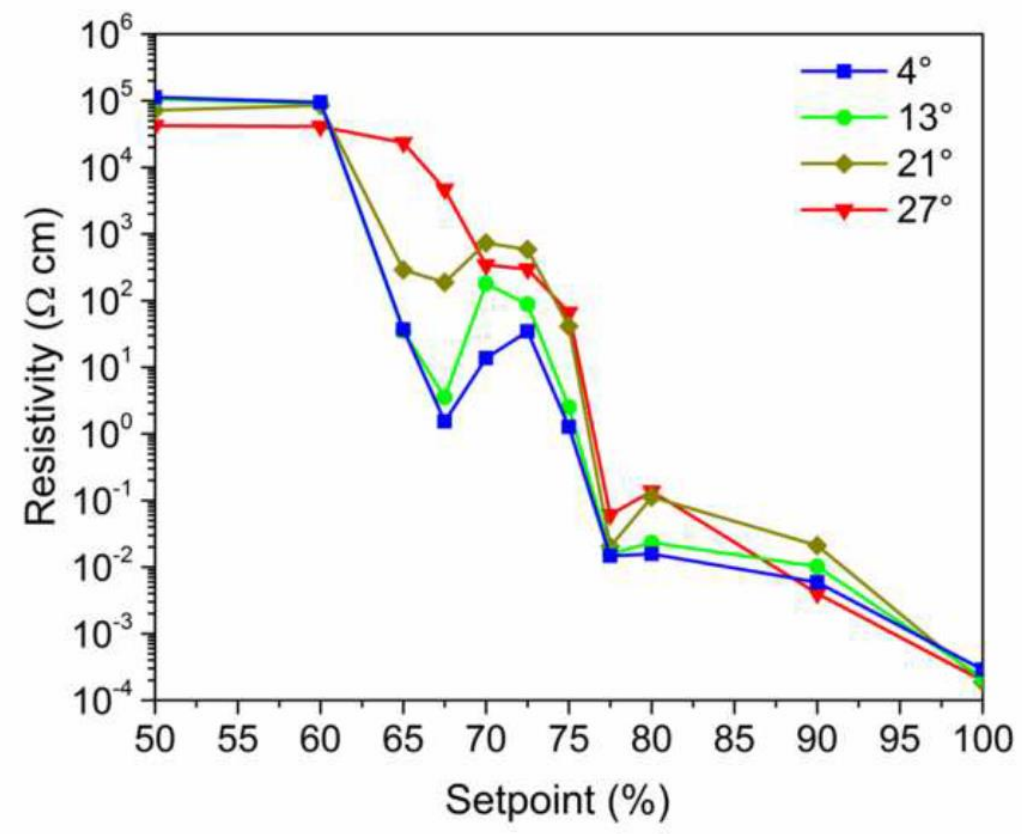


Fig. 6
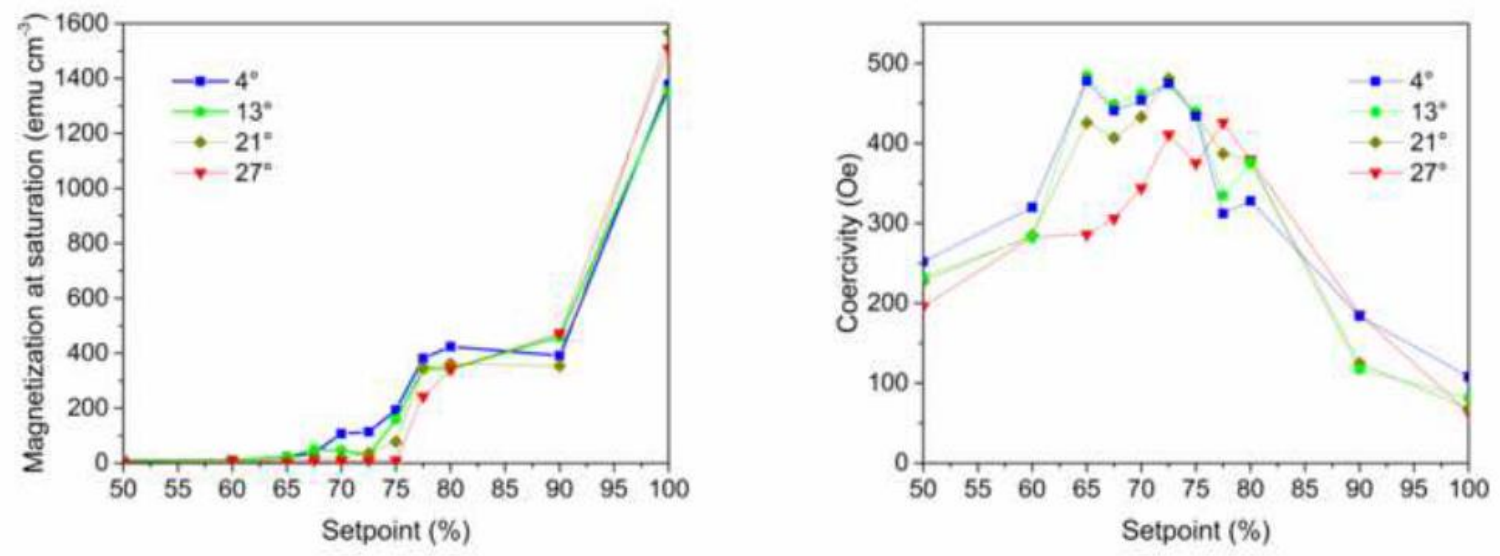